\title{
Speed reading using Spritz has a cost: limits when reading a short text
}

\section{Orlando Ricciardi and Gabriele Calvani}

Department of Psychology, Sapienza University of Rome, Via dei Marsi 78 - 00185 Rome, Italy Email: Orlando.ricciardi@uniromal.it

Email: gabrielecalvani@gmail.com

\section{Francisco Palmero}

Department of Basic Psychology, Clinical and Psychobiology, Faculty of Health Sciences,

Universitat Jaume I,

12071 Castellón de la Plana, Castellón, Spain

Email: palmero@uji.es

\section{James F. Juola}

Department of Psychology, Autonomous University of Madrid Ciudad Universitaria de Cantoblanco, Madrid, Spain

Email: juolas@ku.edu

\section{Francesco Di Nocera*}

Department of Psychology,

Sapienza University of Rome,

Via dei Marsi 78 - 00185 Rome, Italy

Fax: $+30(06) 49917711$

Email:dinocera@uniroma1.it

*Corresponding author

\begin{abstract}
Rapid serial visual presentation (RSVP) can be used to present text one or a few words at a time to a central position on a display. Recent studies using Spritz, a recent application of RSVP, seem to indicate a speed-comprehension trade-off beginning at about a 250 word per minute (wpm) rate when reading a text for more than five minutes. The objective of the present experimental study is to compare inferential comprehension when subjects read in a traditional way or using Spritz at different nominal frequency rates $(250,350$, and $450 \mathrm{wpm})$. Results confirm a comprehension difficulty even in a very short text when the presentation rate exceeds $250 \mathrm{wpm}$. This result should be considered as a guideline to set the optimal presentation rate when reading a short text on a personal device (such as a smartphone or smartwatch) using Spritz.
\end{abstract}


Keywords: reading; rapid serial visual presentation; RSVP; comprehension; workload; Spritz.

Reference to this paper should be made as follows: Ricciardi, O., Calvani, G., Palmero, F., Juola, J. and Di Nocera, F. (xxxx) 'Speed reading using Spritz has a cost: limits when reading a short text', Int. J. Human Factors and Ergonomics, Vol. X, No. Y, pp.xxx-xxx.

Biographical notes: Orlando Ricciardi received his $\mathrm{PhD}$ in Psychology from the Sapienza University of Rome, Italy, where he currently serves as a postdoctoral researcher. He is a member of the Eye-Tracking Laboratory, a facility of the Department of Psychology, where he is involved in several research tracks, including reading, vigilance, and mental workload.

Gabriele Calvani received his Master in Communication and Marketing Psychology from the Sapienza University of Rome, Italy. He has been involved at the Universitat Jaume I of Castellónin a European Project in collaboration with Erasmus + regarding emotional intelligence.

Francisco Palmero received his $\mathrm{PhD}$ in Psychology from the University of Valencia, Spain. He is currently a Full Professor at the Universitat Jaume I of Castellón. His field of work is motivation and emotion. He leads the laboratory of emotions and psychophysiology.

James F. Juola received his $\mathrm{PhD}$ in Psychology from the Stanford University and has held professorships at the University of Kansas and Gettysburg College in the USA, Eindhoven University of Technology in The Netherlands, and the Autonomous University of Madrid in Spain. He has conducted research in the fields of psychophysics, attention, perception, cognition, human-technology interaction, and robotics.

Francesco Di Nocera received his $\mathrm{PhD}$ in Psychology from the Sapienza University of Rome, Italy, where he currently serves as an Associate Professor of Work and Organizational Psychology in the Department of Psychology. He has contributed to the human factors literature with research studies on a variety of topics, including mental workload, human error, and adaptive automation. At the Department of Psychology, he coordinates the activity of the Eye-Tracking Laboratory.

\section{Introduction}

The widespread availability of ever smaller interactive devices, such as tablets, smartphones, smartwatches and bracelets, has generated new environments in which people read. The ubiquity of such devices and their internet connections have led to changes in reading habits, as more people are reading in unusual places and situations (e.g., standing in public transportation or in the dark). The tendency to read on a small device has challenged designers to come up with novel ways to present readable text in confined display areas, as the amount of text available per view is often limited to one or a few lines subtending $12 \mathrm{~cm}$ or less. The need to read in such a small space leads, as a consequence, to the elimination of much potentially useful information from peripheral views. Moreover, on such small displays, the reader has to scroll through the layout very 
frequently, adding a cost for regressions and skipping behaviours. Rapid serial visual presentation (RSVP) is a technique for presenting text one or more words at a time on a display, dramatically reducing the need for eye movements usually involved in the reading process (Forster, 1970; Forster and Ryder, 1971; Holmes and Forster, 1972; Juola et al., 1982; Potter, 1984). Initially proposed as a means for studying cognitive aspects of reading, it was subsequently tested as a way to increase reading speed. This hypothesis relied on the idea that some aspects of eye movements might not be optimal for sampling information from a text. However, many studies have found a trade-off between increasing the reading speed and the level of text comprehension (e.g., Juola et al., 1982; Just and Carpenter, 1980; Potter, 1984; Potter et al., 1980; Rayner et al., 2016). These original results showing a decrease in comprehension as RSVP rates increase has been confirmed recently, making use of a new RSVP application that has renewed interest in RSVP (Acklin and Papesh, 2017; Benedetto et al., 2015; Boo and Conklin, 2015; Di Nocera et al., 2018; Ricciardi and Di Nocera, 2017). Results of these studies are summarised in Table 1.

Table 1 Recent results of comparisons between traditional reading layout (T) and a new RSVP application (Spritz)

\begin{tabular}{|c|c|c|c|c|}
\hline Study & $\begin{array}{l}\text { Text length } \\
\text { (words) }\end{array}$ & $\begin{array}{c}\text { Nominal } \\
\text { presentation rate } \\
\text { (wpm) tested }\end{array}$ & $\begin{array}{l}\text { Comprehension } \\
\text { measured }\end{array}$ & Result \\
\hline $\begin{array}{l}\text { Benedetto et al. } \\
\text { (2015) }\end{array}$ & 6160 & 250 & $\begin{array}{l}\text { literal, } \\
\text { inferential }\end{array}$ & $\begin{array}{c}\mathrm{T}>\text { Spritz (only for } \\
\text { literal } \\
\text { comprehension) }\end{array}$ \\
\hline \multirow[t]{2}{*}{$\begin{array}{l}\text { Boo and Conklin } \\
(2015)\end{array}$} & 500 & $500,1,000$ & detail, gist & $\begin{array}{c}\mathrm{T}>\text { Spritz at } 1,000 \\
\mathrm{wpm}\end{array}$ \\
\hline & & & & $\begin{array}{c}\mathrm{T}>\text { Spritz at } 500 \\
\text { wpm (only for } \\
\text { detailed questions) }\end{array}$ \\
\hline $\begin{array}{l}\text { Ricciardi and } \\
\text { Di Nocera (2017) }\end{array}$ & 5,804 & 250,450 & inferential & $\begin{array}{c}\mathrm{T}>\text { Spritz at } \\
450 \mathrm{wpm}\end{array}$ \\
\hline $\begin{array}{l}\text { Acklin and } \\
\text { Papesh (2017) }\end{array}$ & 230 & $700,1,000$ & $\begin{array}{l}\text { literal, } \\
\text { inferential }\end{array}$ & $\mathrm{T}>$ Spritz \\
\hline $\begin{array}{l}\text { Di Nocera et al. } \\
(2018)\end{array}$ & 5,804 & $\begin{array}{c}250,300,350 \\
400,450\end{array}$ & inferential & $\begin{array}{c}\mathrm{T}>\text { Spritz at } \\
450 \mathrm{wpm}\end{array}$ \\
\hline
\end{tabular}

This application, named Spritz, promised to increase the reading speed that can be achieved with traditional RSVP by eliminating eye movements. The main Spritz innovation is the introduction of an Optimal Recognition Point, already known as the optimal viewing position (OVP; O'Regan et al., 1984). The letter that corresponds to the OVP is highlighted in red and the streaming words are centred on it. Fixations near the centre of a word (the OVP) allow the reader more efficient recognition of a word presented in isolation compared with fixations on more external letters (O'Regan et al., 1984). The advantage is only a few milliseconds (ms), but that is a significant amount of time when reading at very high presentation rates. For example, we can spend an average of $240 \mathrm{~ms}$ on a word when reading at $250 \mathrm{wpm}$, but only $60 \mathrm{~ms}$ if reading at $1000 \mathrm{wpm}$. Based on the OVP, Spritz aligns all the words on the central letter. Furthermore, longer 
words are displayed for longer times, and longer sentences have longer pauses at their ends.

\subsection{Speed-comprehension trade-off using Spritz}

A recent study by Schotter et al. (2014) has confirmed an advantage for reading comprehension when the readers have the opportunity to control their eye movements. Reading normally (regressions allowed) resulted in better comprehension compared with reading in the trailing mask condition, a technique that disallows the rereading of a word (regressions not allowed). In the trailing mask condition, each word is masked after the reader fixates the word and makes a forward saccade away from it (i.e., each letter in previous words was replaced with an $\mathrm{x}$ ). Then, the masked words remained masked even if the reader were to look back at it.

As in earlier studies of RSVP reading, those conducted using Spritz have found an impairment in comprehension when the presentation rate exceeds about $250 \mathrm{wpm}$ (Benedetto et al., 2015; Ricciardi and Di Nocera, 2017) or $350 \mathrm{wpm}$ (Di Nocera et al., 2018). Benedetto et al. (2015) compared comprehension (and other aspects of reading experience including task load, visual fatigue, performance, and ocular behaviour) between RSVP at a $250 \mathrm{wpm}$ rate and regular reading with eye movements. The first chapter of a novel (Orwell, 2004) was used as text, which was about 6160 words in length ("the whole text was displayed on 44 pages of 20 lines each with an average of 140 words per page" p.354). Subjects were allowed to make pauses whenever needed to cope with the length of the reading session. Results showed a lower level of literal comprehension for the Spritz RSVP method than for traditional reading, but no differences were found for inferential comprehension. This result indicates that increasing reading speed without a loss of comprehension is not easily obtainable. A limit of the Benedetto et al. (2015) study is the lack of a faster presentation rate condition that would be useful to understand the limits of inferential comprehension using Spritz. The authors did not test reading speeds above $250 \mathrm{wpm}$, "which roughly correspond to the average reading speed for French readers who silently read a text with the aim of learning it" (p.354). Another limitation is the generalisability of results obtained on a very long text that may affect the ability to extract and store information in short- and long-term memory. A study by Boo and Conklin (2015) using a concise text confirmed a comprehension impairment in reading with Spritz at high presentation rates (faster than $500 \mathrm{wpm})$. They compared native and non-native English speakers using three rates of $500 \mathrm{wpm}, 1000 \mathrm{wpm}$ and their own pace while reading three shortened texts from the Cambridge Instant IELTS (Brook-Hart, 2004) of less than 500 words (the range was 409 to 485 words), and comprehension was assessed by using detailed questions and gist questions. Focusing only on native speakers, readers answered the questions more accurately after reading at their own pace than after reading at $1000 \mathrm{wpm}$. When subjects read at $500 \mathrm{wpm}$, the same difference was found for detailed questions, but not for gist. Unfortunately, the authors did not report the average reading speed for readers in their own pace condition, so it is difficult to understand the magnitude of the comprehension impairment. However, the study seems to confirm what Benedetto and colleagues found regarding the differences between responses to detailed and inferential comprehension questions. Indeed, Benedetto et al. (2015) used a similar methodology to assess comprehension using both literal (or detailed) questions and inferential (or gist) ones. Results of this study were similar to those of Boo and Conklin (2015), confirming a 
difficulty for subjects using RSVP to store specific information extracted from the text in working memory. On the other hand, responses to inferential or gist questions seem to avoid this difficulty by allowing the reader to integrate and retrieve information from long-term memory. Indeed, Benedetto et al. (2015) found no differences between traditional reading and reading at $250 \mathrm{wpm}$ and, more clearly, Boo and Conklin found no differences between reading at one's own pace and reading RSVP at $500 \mathrm{wpm}$. A limitation of the Boo and Conklin (2015) study is that comprehension assessment relied on only a few questions. Each questionnaire consisted of five questions, so detail and gist comprehension were assessed by using only 2 or 3 questions each, and readers had a . 25 probability of correctly answering by chance (questionnaires are available in the appendix of the Boo and Conklin manuscript). Acklin and Papesh (2017) made another study comparing the normal (static) reading with RSVP using Spritz. They reported an experiment in which participants had to read two 6th-grade and two 12th-grade passages of the text of approximately 500 words. In a static condition, subjects were allowed to read at their own pace, resulting in an average of $220 \mathrm{wpm}$, and in RSVP conditions the texts were presented at 700 and $1000 \mathrm{wpm}$. Verbatim and inferential comprehension results were better in static condition than in RSVP at 700 and 1000 wpm. Even though the authors stated that "our results demonstrated comprehension deficits after the rapid presentation of text passages", differences in the rate compared for static $(220 \mathrm{wpm})$ and RSVP (700 and 1,000 wpm) may be due to the confounding of presentation format and reading speed, as noted by Juola (2018).

\section{The present study}

In the present study, we compared a normal reading condition (control) with three RSVP rates, testing the null hypotheses that no comprehension differences would be found between the control condition and RSVP at 250 and $350 \mathrm{wpm}$. We made no hypothesis for the comparison between the control condition and RSVP at $450 \mathrm{wpm}$. However, this presentation rate had resulted in an important comprehension decline in our previous studies (Di Nocera et al., 2018), so it was decided to include the same rate in the present work. In these studies, an inferential comprehension test was given after subjects read a long text (about 30 minutes of reading in the control reading condition). The specific objective of the present study is to compare that result after reading a short text (about seven minutes of reading in the control reading condition).

\section{Materials and methods}

\subsection{Participants}

120 students $(82$ females, mean age $=19.1$ years, S.D. $=3.2$ ) were recruited in exchange for a one-point bonus in an exam evaluation. All subjects had a normal or corrected-tonormal vision. All were native Spanish speakers, were naïve as to the aims of the experiment, its expected outcomes, and its methodology. Participants were equally divided into four groups corresponding to the four experimental conditions. This research complied with the tenets of the Declaration of Helsinki and was approved by the 
Institutional Review Board at the Department of Basic Psychology, Universitat Jaume I, Spain. Informed consent was obtained from each participant.

\subsection{Apparatus}

The RSVP streaming was implemented through Spreed, a plugin available for the Chrome browser (https://chrome.google.com/webstore/detail/spreed-speed-read-theweb/ipikiaejjblmdopojhpejjmbedhlibno). Spreed is based on Spritz technology (Waldman et al., 2013). In Spritz-based software applications, the actual reading speed differs from the nominal one and is different from text to text because it is influenced by factors such the lengths of the words and the lengths of the sentences. As a result, longer words are displayed longer, and longer sentences have longer pauses at their ends (see Maurer and Locke, 2014, for further details). With the text used in this experiment, the $250 \mathrm{wpm}$ condition resulted in an actual presentation rate of $195 \mathrm{wpm}$, the $350 \mathrm{wpm}$ condition produced a $270 \mathrm{wpm}$ rate, and the $450 \mathrm{wpm}$ condition resulted in actual rate of $345 \mathrm{wpm}$ (a summary of this information is available in Table 2).

Variables such as font size (60") and type (Serif) were not manipulated and were kept constant during across the experimental conditions. The average distance between participants and the screen employed for the reading task was $70 \mathrm{~cm}$. The screen size was 433 (horizontal) $\times 447$ (vertical) $\mathrm{mm}$. Screen resolution was set to $1,280 \times 1,024 \mathrm{px}$. The horizontal visual angle of a four-letter word was about $1^{\circ}$.

Table 2 Differences between RSVP nominal speed and Spritz actual rate

\begin{tabular}{lccc}
\hline $\begin{array}{l}\text { Presentation nominal } \\
\text { rates (wpm) }\end{array}$ & $\begin{array}{c}\text { RSVP nominal time } \\
\text { (min, sec) }\end{array}$ & $\begin{array}{c}\text { Presentation actual } \\
\text { rates (wpm) }\end{array}$ & $\begin{array}{c}\text { Spritz effective time } \\
\text { (min, sec) }\end{array}$ \\
\hline 250 & 5.21 & 195 & 6.51 \\
350 & 3.50 & 268 & 5 \\
450 & 2.58 & 346 & 3.50 \\
\hline
\end{tabular}

Notes: Text length was 1,337 words. The average time in the control-reading condition was 7 minutes and 50 seconds (about $167 \mathrm{wpm}$ ).

\subsection{Experimental design and procedure}

Participants were randomly assigned to one of four experimental conditions in a between-subjects experimental design: Traditional reading $(\mathrm{N}=30)$, Spritz $195 \mathrm{wpm}$ $(\mathrm{N}=30)$, Spritz $268 \mathrm{wpm}(\mathrm{N}=30)$, and Spritz $346 \mathrm{wpm}(\mathrm{N}=30)$. All participants underwent a practice session before experimentation, reading a 607 -word article 'Las ciudadesflotantes' on the online version of 'El Pais' (available at http://elpaissemanal.elpais.com/documentos/ciudades-flotantes/). After training, we asked participants to read the online version of the 'Comer comonunca' (available at https://elpais.com/elpais/2016/08/12/ciencia/1471003949_965481.html) and informed them about the following comprehension test. The article length was 1,337 words. Participants in the Traditional condition were instructed to read at their own pace, resulting in an average reading time of about 8 minutes (or about $167 \mathrm{wpm}$ ). Other participants read at the Spritz actual rate, resulting in approximately seven, five and four minutes respectively for 195, 268 and $346 \mathrm{wpm}$ conditions (a summary of this information is available in Table 2). Readability of the experimental text was assessed 
using the widely-used Flesch-Kincaid Grade Level (FKGL; Flesch, 1948). The text obtained a 21.3 score, indicating that it was suitable for college students (15.5-grade level). Ambient lighting and screen luminance were kept constant, and pauses were not allowed during the experiment.

\subsection{Comprehension questionnaire}

A questionnaire was created ad hoc for this study to assess the participants' inferential comprehension. The questions were designed to determine inferential comprehension, presumably based on the readers' ability to understand the textual information presented in the article and to make valid inferences regarding related concepts. The questionnaire was composed of 15 true/false questions, of which seven were true, and eight were false. Each question was related to a specific range of text (about 91 words). The order of questions was randomised to avoid guessing due to temporal relations between the text and questions. The following is the English translation (made by the authors) of an excerpt of 'Comer comonunca' by Martín Caparrós that was used for reading in the study reported here:
"And, this world cannot, does not support waste, there is not enough for everyone. It is likely that a solution is starting to cook, little by little, not in fields or stables, but in laboratories: new forms of food production that will change the ideas of how food is produced, which will do without plants and animals, which will be, probably, a revolution as decisive as the invention of agriculture. Once again, we will eat like never before. It is already possible, for example, to produce real meat by cloning meat cells: for now, the problem is that it costs too much, but, surely, in a few years it will be able to compete with pigs and cows. Moreover, if it succeeds, so much land that the cattle now occupy will be free for other production and so many plants that they eat will be food for others, and so much $\mathrm{CO} 2$ that their flatus produces will no longer heat the planet, and so on: the famous domino effect, the unpredictable. It will be - perhaps - another great moment in history. It already appears, and, for now, it is in the hands of large and small companies, mostly North American, its technicians, its laboratories, which think about making food to make money. It already appears, and, for that reason, it is worth it, of course, to begin to discuss who will handle it, who will win with those changes: that eating as never before is not, once again, to plunder as always."

Questions related to the excerpt above were presented in a true/false format, as in the following examples:

- Currently, cloning meat cells is much cheaper than buying meat

- The way American companies deal with food is exclusively oriented towards economic profit rather than sustainability.

\subsection{Nasa TLX}

The NASA-Task Load Index (NASA-TLX; Hart and Staveland, 1988), is a multidimensional rating technique that requires ratings on six individual dimensions (mental demand, physical demand, temporal demand, effort, performance, and frustration) that are assumed to be related to subjective workload. Ratings on the six individual dimensions are combined through a prescribed procedure to provide an overall 
index of the workload associated with a task or function. Previous research with TLX has demonstrated its sensitivity to variations in workload while flying an aircraft during landing or in other interactions with complex systems (e.g., Eggemeier and Wilson, 1991; Hart and Wickens, 1990; Lysaght et al., 1989), but it has not addressed some essential methodological issues regarding its application (e.g., vulnerability to context effects). Its main advantages are its ease of use and the short time needed to fill in the form and to compute the ratings, not to mention its low cost. However, a limitation of this tool is its inability to collect continuous, on-line information about the state of an individual, but only providing a subjective measurement in discrete periods.

\section{Results}

The arcs in transformations of the proportions of correct responses were used as the dependent variable in an ANOVA design using Condition (T vs 195 wpm Spritz vs 268 wpm Spritz vs 346 wpm Spritz) as the single factor. Results showed a significant effect of condition, $F_{3,116}=10.05, p<.001, \eta 2 \mathrm{p}=.22$, and the observed power was 1 . Post-hoc testing using the Bonferroni $t$ statistic showed no differences between comprehension scores for traditional reading and reading with Spritz at $195 \mathrm{wpm}$, whereas there were significant differences when the presentation rate was increased above $195 \mathrm{wpm}$. In particular, the scores for Traditional reading were significantly different from those at the 268 and 346 wpm conditions $(p<.01)$, whereas those for $195 \mathrm{wpm}$ were significantly higher than the scores from the $346 \mathrm{wpm}$ condition $(p<.01)$. The data reporting the comprehension results for the actual wpm conditions are shown in Figure 1.

Figure 1 Mean percentage of comprehension scores obtained across conditions on the inferential comprehension questionnaire (chance performance $=50 \%$ )

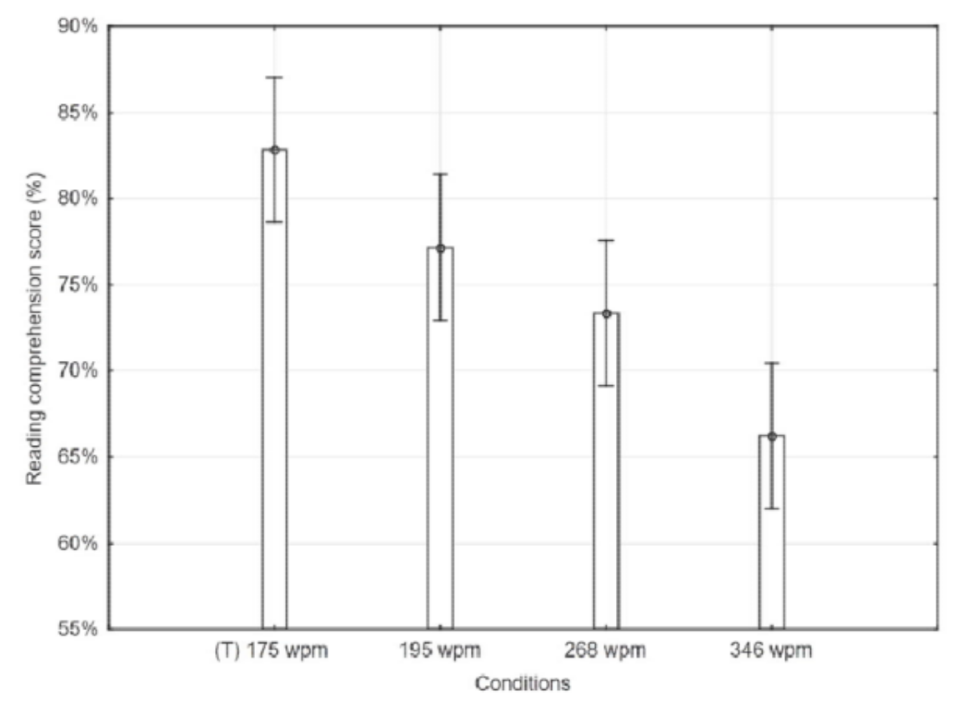

Note: Vertical bars denote $95 \%$ confidence intervals. 
Nasa TLX scores (overall scores) were also used in an ANOVA design using Condition (T vs. 195 wpm Spritz vs 268 wpm Spritz vs $346 \mathrm{wpm}$ Spritz) as a factor. Analyses showed a significant effect of condition, $F_{3,116}=22.74, p<.001, \eta 2 \mathrm{p}=.37$, and the observed power was 1 . Post-hoc testing using the Bonferroni $t$ statistic showed no differences between the Spritz conditions at 268 vs. 346 wpm, whereas all other conditions resulted in significant differences $(p<.01)$. This result clearly shows a direct relationship between the increasing wpm rate and the perceived mental workload (see Figure 2).

Figure 2. Reported mental workload using Nasa TLX

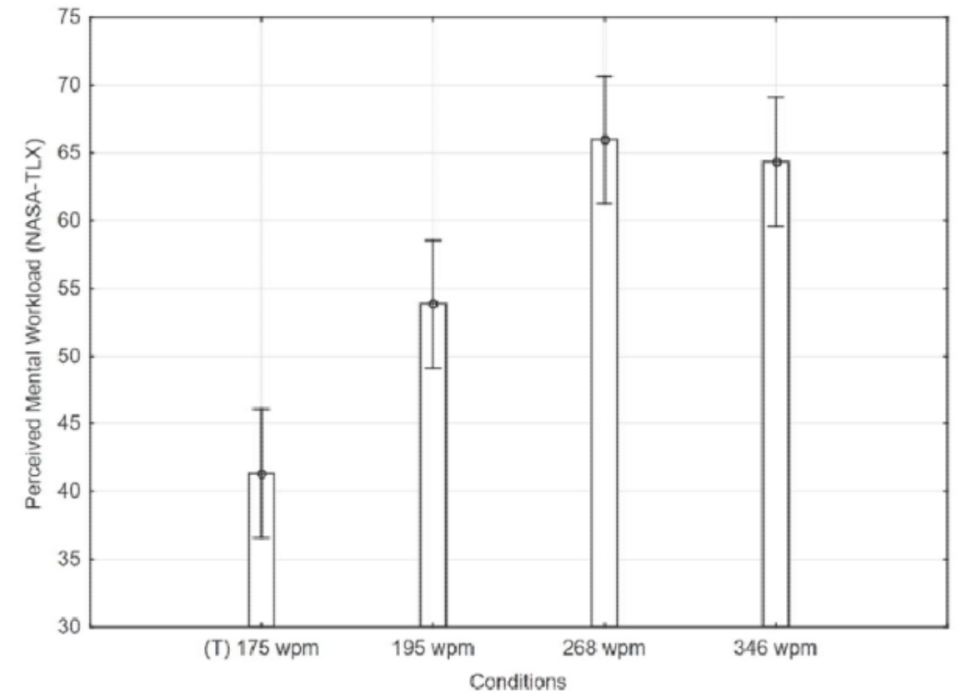

Note: Vertical bars denote .95 confidence intervals.

Table 3 Bonferroni post-hoc testing for each NASA-TLX sub-scale

\begin{tabular}{lcc}
\hline NASA-TLX sub-scales & Statistic Bonferroni comparison & $p$ value* \\
\hline Mental demand & $\mathrm{T}<268$ wpm Spritz & $\mathrm{p}<.001$ \\
& $\mathrm{~T}<346$ wpm Spritz & $\mathrm{p}<.001$ \\
Temporal demand & $\mathrm{T}<268$ wpm Spritz & $\mathrm{p}<.001$ \\
& $\mathrm{~T}<346$ wpm Spritz & $\mathrm{p}<.001$ \\
& 195 wpm Spritz $<268$ wpm Spritz & $\mathrm{p}<.01$ \\
Physicaldemand & 195 wpm Spritz $<346$ wpm Spritz & $\mathrm{p}<.001$ \\
Effort & $\mathrm{T}<268$ wpm Spritz & $\mathrm{p}<.01$ \\
& $\mathrm{~T}<268$ wpm Spritz & $\mathrm{p}<.001$ \\
Frustration & $\mathrm{T}<346$ wpm Spritz & $\mathrm{p}<.001$ \\
& $\mathrm{~T}<268$ wpm Spritz & $\mathrm{p}<.001$ \\
\hline
\end{tabular}

Note: *Bonferroni's adjustment requires to lower the .05 to .0083 . 
NASA-TLX sub-scales scores were tested in a MANOVA design using condition (T vs. $195 \mathrm{wpm}$ Spritz vs. $268 \mathrm{wpm}$ Spritz vs. $346 \mathrm{wpm}$ Spritz) as factor. Results showed a significant effect of condition, Wilks' $\lambda=.52, \mathrm{~F}=4.55, p<.001$. Univariate analyses for each sub-scale confirmed a difference between the conditions $\mathrm{T}$ and Spritz at highest frequency rate (268 wpm and $346 \mathrm{wpm}$ ) for all sub-scales except for Performance. The analyses also confirmed the absence of a significant difference between $268 \mathrm{wpm}$ and $346 \mathrm{wpm}$ Spritz conditions. The $195 \mathrm{wpm}$ Spritz condition resulted significantly different from the other two only for the temporal demand sub-scale.

\section{Discussion}

RSVP is a technique proposed to study cognitive processes while reading by reducing eye movement by presenting one or more words at a time in the centre of the screen. This layout reduces the number of saccades and eliminates the typical backwards and forward eye movements occurring during reading, which is potentially sometimes inaccurate and resource-consuming. Contrary to this assumption, several studies have demonstrated the importance of eye movements for integrating and elaborating information (Castelhano and Muter, 2001; Primativo et al., 2016; Rayner et al., 2016; Schotter et al., 2014), with particular importance for parafoveal preview and regressions.

The state of the art does not show a clear perspective about the possible benefits of using RSVP for reading, especially considering the introduction of the OVP for singleword displays used in the Spritz application. The variables of presentation rate, text length and difficulty limit the generalisability of results found in previous studies. For example, when overall wpm was equated, Juola et al.(1982) found similar comprehension scores between normal reading and RSVP. Negative comprehension scores in the RSVP format may be due to an excessive load in working memory that makes it harder to store and retrieve information, especially at higher presentation rates.

If the problem for reading RSVP is an excessive load in working memory, performance should increase for shorter passages read at normal rates, thereby reducing the total amount of information that has to be stored. We tested this hypothesis by comparing comprehension obtained in reading a short text using RSVP or a traditional layout at comparable presentation rates. The results had shown a comprehension decrement when words were presented using Spritz at a rate higher than $195 \mathrm{wpm}$. This seems to be the same effect found when a long text was used in previous studies. Not only does the threshold seem to be the same regardless of the length of the text, but also the percentages of correct answers are very similar. These results indicate that the loss in comprehension for RSVP at higher than normal rates are not caused by the total amount of information that the reader has to store. Indeed, every short text appears to result in similar comprehension patterns as a longer one. To explain this effect, we assume that the comprehension is affected at a perceptual level, so that the reader does not have the time to integrate the information and organise a general understanding of the text when RSVP rates exceed normal reading rates by some fixed amount. It is possible that training could increase the readers' abilities, allowing an increase in the effective word per minute rate. In the present study, participants read a short text to familiarise them with the new technology. This short training was necessary for subjects to understand the RSVP format, but we suggest that a longer training period might be beneficial before testing 
with RSVP. Usually, users of Spritz applications read more than just one content, so it would be more naturalistic to train the reader before the experiment.

The second result of this study is the difference in reported mental workload between traditional and RSVP conditions. In a previous study (Ricciardi and Di Nocera, 2017), the RSVP format was shown to be more demanding than traditional reading regardless of the presentation rates. A possible interpretation for that result can be related to the amount of time required for reading the text. It is possible that reading for more than about 10 minutes using Spritz can be a highly-demanding activity. The results of the current study partially confirm this effect since the subjects had only a few minutes of reading with Spritz. Reading with Spritz was shown to be more demanding than reading in a traditional format. This difference could be predictable because the normal reading of a text for less than 10 minutes is not a particularly demanding activity. Indeed, even Spritz at $195 \mathrm{wpm}$ resulted in higher cognitive load scores than traditional reading, despite resulting in comprehension scores equivalent to those obtained in normal reading at slower rates. A difference from a previous study (Ricciardi and Di Nocera, 2017) is that the $195 \mathrm{wpm}$ condition resulted in lower demand scores than those found for $268 \mathrm{wpm}$ and $346 \mathrm{wpm}$. This effect may be explained by considering the text's length. It is possible that subjects experienced a higher mental workload because they read for only a few minutes. In the previous study, the $346 \mathrm{wpm}$ condition lasted about fifteen minutes, allowing subjects more experience to improve their abilities in reading with Spritz.

The main limitation of this study is the possibility to generalise the results on different texts or populations of readers. RSVP effectiveness may be related to the properties of the text, the reading objective, and the characteristics of the readers. For example, the effectiveness of RSVP may be different for special reader populations, such as visually impaired or dyslexics. Other limitations, that have already been suggested, is that significant training would be likely to increase performance reading RSVP text as well as reducing the subjective workload assessments as readers gained more practice with the task. Finally, it should be considered that there are alternative methods of optimising the readability of text presented in the RSVP format, and Spritz-based method is not necessarily the best available alternative (e.g., Cocklin et al., 1984).

\section{Conclusions}

In conclusion, the present study confirms the difficulty in increasing reading speed using the RSVP format, even when applying the Spritz innovations. It extends the previous results on the relationship between RSVP and comprehension to a short text. While other studies have compared the traditional reading with Spritz at high presentation rates (Acklin and Papesh, 2017; Boo and Conklin, 2015), we have used rates closer to those observed for regular reading, setting Spritz at nominal rates of $250 \mathrm{wpm}, 350 \mathrm{wpm}$ and $450 \mathrm{wpm}$.

We think that further studies could explore the possible benefits of RSVP for different domains than increasing reading speed on a computer. The increasing use of small devices for reading creates new challenges for delivering textual information. At this moment, there is a lack of analyses of eye movements when reading on a small device such as a smartphone. Possible research innovations could improve the RSVP algorithm, assessing the benefit of displaying more than one word at a time, especially if 
longer text segments are chosen to reflect syntactic groupings, when possible (Cocklin et al., 1984). Higher reading speeds can then be obtained while still maintaining relatively long exposure times, thus reducing perceptual overload. Other scholars also suggested using RSVP with specific populations of readers, such as novices, the visually impaired, older adults, and dyslexics (i.e., Castelhano and Muter, 2001; Juola, 1988; Lemarié et al., 2008). Another relevant field is the application of RSVP for reducing the adverse effects of visual crowding, which has been shown to affect object recognition (Whitney and Levi, 2011) and reading speed (Pelli and Tillman, 2008). RSVP could likely be used in such applications as learning to read, assisting children and adults with reading difficulties, second-language learning (perhaps with simultaneous or delayed auditory presentations), besides the obvious use for devices with small viewing screens (Juola et al., 1995).

\section{Acknowledgements}

This research did not receive any specific grant from funding agencies in the public, commercial, or not-for-profit sectors.

\section{References}

Acklin, D. and Papesh, M.H. (2017) 'Modern speed-reading apps do not foster reading comprehension', American Journal of Psychology, Vol. 130, No. 2, pp.183-199.

Benedetto, S., Carbone, A., Pedrotti, M., Le Fevre, K., Bey, L.A. and Baccino, T. (2015) 'Rapid serial visual presentation in reading: the case of Spritz', Computers in Human Behavior, Vol. 45, No. 1, pp.352-358.

Boo, Z. and Conklin, K. (2015) 'The impact of rapid serial visual presentation (RSVP) on reading by nonnative speakers', Journal of Second Language Teaching and Research, Vol. 4, No. 1, pp.111-129.

Brook-Hart, G. (2004) Instant IELTS, Cambridge University Press, Cambridge, UK.

Castelhano, M.S. and Muter, P. (2001) 'Optimizing the reading of electronic text using rapid serial visual presentation', Behaviour \& Information Technology, Vol. 20, No. 4, pp.237-247.

Cocklin, T.G., Ward, N.J., Chen, H-C. and Juola, J.F. (1984) 'Factors influencing readability of rapidly-presented text segments', Memory \&Cognition, Vol. 12, No. 5, pp.431-442.

Di Nocera, F.D., Ricciardi, O. and Juola, J.F. (2018) 'Rapid serial visual presentation: degradation of inferential reading comprehension as a function of speed', International Journal of Human Factors and Ergonomics, Vol. 5, No. 4, pp.293-303.

Eggemeier, F.T. and Wilson, G.F. (1991) 'Performance-based and subjective assessment of workload in multi-task environments', Multiple-task Performance, pp.217-278, Taylor \& Francis, London.

Flesch, R. (1948) 'A new readability yardstick', Journal of Applied Psychology, Vol. 32, No. 3, p.221.

Forster, K.I. (1970) 'Visual perception of rapidly presented word sequences of varying complexity', Attention, Perception and Psychophysics, Vol. 8, No. 4, pp.215-221, DOI: $10.3758 / \mathrm{BF} 03210208$.

Forster, K.I. and Ryder, L.A. (1971) 'Perceiving the structure and meaning of sentences', Journal of Verbal Learning and Verbal Behavior, Vol. 10, No. 3, pp.285-296. 
Hart, S.G. and Staveland, L.E. (1988) 'Development of NASA-TLX (task load index): results of empirical and theoretical research', in Hancock, P.A. and Meshkati, N. (Eds.): Human Mental Workload, pp.139-183, North-Holland, Oxford, UK.

Hart, S.G. and Wickens, C.D. (1990) Workload Assessment and Prediction, in Manprint, pp.257-296, Springer, Dordrecht.

Holmes, V.M. and Forster, K.I. (1972) 'Perceptual complexity and underlying sentence structure', Journal of Verbal Learning and Verbal Behavior, Vol. 11, No. 2, pp.148-156.

Juola, J.F. (1988) 'The use of computer displays to improve reading comprehension', Applied Cognitive Psychology, Vol. 2, No. 1, pp.87-95.

Juola, J.F. (2018) 'Give RSVP a chance: reply to Acklin and Papesh', American Journal of Psychology, Vol. 131, No. 2, pp.225-226.

Juola, J.F., Tiritoglu, A. and Pluenis, J. (1995) 'Reading text presented on a small display', Applied Ergonomics, Vol. 20, No. 3, pp.227-229.

Juola, J.F., Ward, N.J. and McNamara, T. (1982) 'Visual search and reading of rapid serial presentations of letter strings, words, and text', Journal of Experimental Psychology: General, Vol. 111, No. 2, p.208.

Just, M.A. and Carpenter, P.A. (1980) 'A theory of reading: from eye fixations to comprehension', Psychological Review, Vol. 87, No. 4, p.329.

Lemarié, J., Eyrolle, H. and Cellier, J.M. (2008) 'The segmented presentation of visually structured texts: effects on text comprehension', Computers in Human Behavior, Vol. 24, No. 3, pp.888-902.

Lysaght, R.J., Hill, S.G., Dick, A.O., Plamondon, B.D. and Linton, P.M. (1989) Operator Workload: Comprehensive Review and Evaluation of Operator Workload Methodologies, No. TR-2075-3, Analytics Inc., Willow Grove, PA.

Maurer, M.S. and Locke, J. (2014) Why Spritz Works: It's All about the Alignment of Words [online] http://www.spritzinc.com (accessed June 2016).

O'Regan, J.K., Lévy-Schoen, A., Pynte, J. and Brugaillère, B.É. (1984) 'Convenient fixation location within isolated words of different length and structure', Journal of Experimental Psychology: Human Perception and Performance, Vol. 10, No. 2, p.250.

Orwell, G. (2004) 1984 [online] https://www.ebooksgratuits.com/ (accessed June 2016).

Pelli, D.G. and Tillman, K.A. (2008) 'The uncrowded window of object recognition', Nature Neuroscience, Vol. 11, No. 10, p.1129.

Potter, M.C. (1984) 'Rapid serial visual presentation (RSVP): a method for studying language processing', in Kieras, D. and Just, M. (Eds.): New Methods in Reading Comprehension Research, pp.91-118, Erlbaum, Hillsdale, NJ.

Potter, M.C., Kroll, J.F. and Harris, C. (1980) 'Comprehension and memory in rapid sequential reading', in Nickerson, R.S. (Ed.): Attention and Performance, Vol. 8, pp.395-418, Erlbaum, Hillsdale, NJ.

Primativo, S., Spinelli, D., Zoccolotti, P., De Luca, M. and Martelli, M. (2016) 'Perceptual and cognitive factors imposing 'speed limits' on reading rate: a study with the rapid serial visual presentation', PloS one, Vol. 11, No. 4, p.e0153786.

Rayner, K., Schotter, E.R., Masson, M.E., Potter, M.C. and Treiman, R. (2016) 'So much to read, so little time: how do we read, and can speed reading help?', Psychological Science in the Public Interest, Vol. 17, No. 1, pp.4-34.

Ricciardi, O. and Di Nocera, F. (2017) 'Not so fast: a reply to Benedetto et al. (2015)', Computers in Human Behavior, Vol. 69, No. 1, pp.381-385.

Schotter, E.R., Tran, R. and Rayner, K. (2014) 'Don't believe what you read (only once) comprehension is supported by regressions during reading', Psychological Science, Vol. 25, No. 6, pp.1218-1226.

Waldman, F.A., Maurer, M.S. and Skrypnyuk, O. (2013) U.S. Patent Application No.13/973,867. 
Whitney, D. and Levi, D.M. (2011) 'Visual crowding: a fundamental limit on conscious perception and object recognition', Trends in Cognitive Science, Vol. 15, No. 4, pp.160-168. 